\title{
Novos públicos, dialetos e ESG: a inflexão da comunicação financeira no Brasil
}

New audiences, dialects, and ESG: financial communication inflection in Brazil

Nuevos públicos, lenguajes y ESG: la inflexión de la comunicación financiera en Brasil

Entrevista

Geraldo Soares

Ágatha Paraventi

- Doutora e Mestre em Ciências da Comunicação pela Escola de Comunicações e Artes da Universidade de SãoPaulo (ECA-USP).

- $\quad$ Professora da ECA-USP.

- Professora da Faculdade Cásper Líbero.

- E-mail: agathacamargo@yahoo.com.br

(9) Luiz Alberto de Farias

- Livre-docente pela ECA-USP.

- Doutor em Comunicacãa e Cultura pela USP.

- Professor associado da ECA-USP e professor Titular da Universidade Metodista de São Paulo.

- E-mail: lafarias@usp.br

Valéria de Siqueira Castro Lopes

- Doutora e Mestre em Ciências da Comunicação pela ECA-USP.

- Professora da ECA-USP.

- Professora Titular da Faculdade Cásper Líbero.

- Docente do curso Gestão Estratégica em Comunicação Organizacional e Relações Públicas -

- GESTCORP/ECA-USP.

- E-mail: valeriacastro@usp.br 


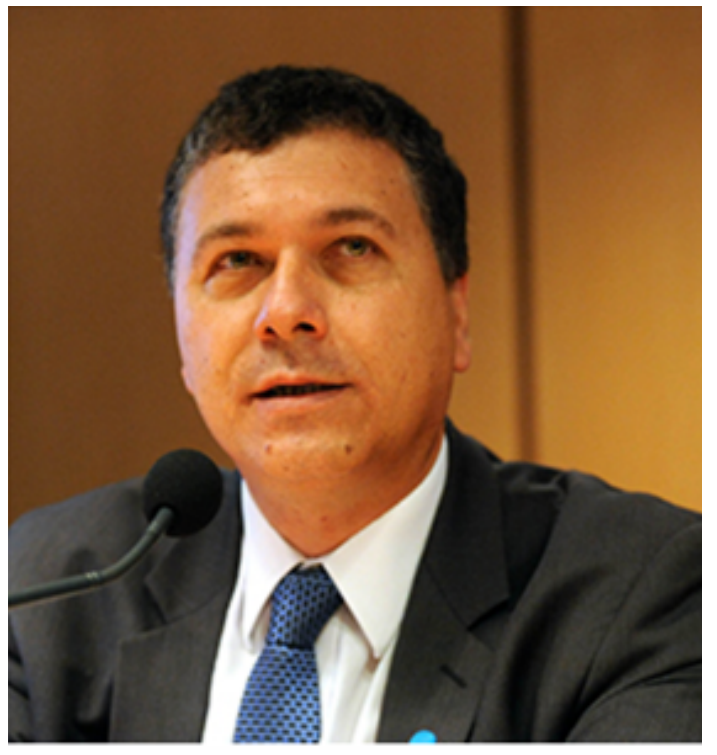

\section{Geraldo Soares}

- $\quad$ Superintendente de relações com investidores do Itaú Unibanco.

- $\quad$ Conselheiro do Conselho de Administração do Instituto Brasileiro de Relações com Investidores - IBRI.

- Ex-Presidente do Conselho de Supervisão de Analistas de Valores Mobiliários da Associação dos analistas e profissionais de investimento do mercado de capitais - APIMEC.

- Ex-coordenador da Comissão de Comunicação e Mercado de Capitais do IBGC.

- Autor de dois Livros: Comunicação no Mercado Financeiro: um guia para relações com investidores, editora Saraiva, 2010; e Casos de Suce\$\$o no Mercado de Ações - aprenda com quem venceu nas altas e baixas da Bolsa de Valores, editora Elsevier, 2011.

- Membro e coordenador do Comitê Superior de Orientação, Nominação e Ética do IBRI.

- Membro do Conselho Diretor da Abrasca.

- Email: geraldosoares9@terra.com.br 
A Iguns segmentos são mais fechados que outros. A comunicação pode ser um desses portões, dessas trancas que impedem que os públicos consigam estabelecer relações de confiança. Quando nos referimos aos chamados "mercados", automaticamente vem à cabeça a ideia de estamos falando dos mercados financeiros. E, sim, esse é um segmento que tem entre si e o público em geral mais do que um portão, mas um fosso: linguagens altamente técnicas, jargões especializados, predisposição ao silêncio. Essas talvez sejam impressões de boa parte das pessoas, mas se até há pouco tempo tratava-se de diálogo entre iguais, nos últimos anos o mercado financeiro passou a ter entre seus investidores pessoas que não conhecem a linguagem própria do setor, mas entram com seu capital e o desejo de conhecer um pouco mais. Afinal, a comunicação pode ser um lenitivo para os que procuram navegar em novos mares. Remotamente, respeitando o distanciamento social e as regras sanitárias tão essenciais, a ORGANICOM conversou com Geraldo Soares, executivo altamente especializado no mercado financeiro e que nos traz um olhar profundo sobre a comunicação no mercado financeiro. Soares nos conta como as empresas ligadas a investimentos - e todas aquelas que precisam se comunicar com investidores dos mais diferentes perfis - estão aprendendo a ajustar o discurso e a transformar as narrativas inalcançáveis à boa parte das pessoas em uma comunicação clara e confiável. Afinal, comunicação é elemento importante para gerar confiança e quando se fala de investimento, confiança é palavra-chave.

Soares demonstra como novas práticas têm sido adotadas ao longo dos anos e especialmente como a pandemia que enfrentamos nestes sofridos anos de covid-19 ensinaram novos modelos de comportamento e de gestão. Além disso, dicas e experiências nos são compartilhadas do alto de muita experiência lidando com mercados de alto nível de especialização e competitividade e ao mesmo tempo com pessoas comuns, que querem apenas crer se podem ou não dormir tranquilas, mesmo sem entenderem ao certo as estratégias adotadas para os seus investimentos.

ORGANICOM - A comunicação financeira era entendida como área que dialogava pouco com os públicos, uma linguagem pouco clara, fechada. Contudo, temos observado tentativas de simplificar a compreensão do setor, como por exemplo o relato integrado e outros mecanismos que unificam informações. Como você observa a evolução da comunicação financeira nos últimos anos?

GERALDO SOARES - Vejo que as mudanças podem ser paulatinas ou por momentos de inflexão. Nesse sentido, vejo duas coisas que aconteceram recentemente no Brasil e no mundo que mudaram o perfil do investidor e a área de comunicação financeira drasticamente. Mudamos e não voltará ao que era antes. Quais são as duas questões: a primeira é a taxa de juros no Brasil. Tal queda fez que uma gama gigantesca de brasileiros começasse a comprar ações. As empresas começaram a ter um fluxo de pessoas físicas muito maior. 0 número cresceu 10 vezes, 20 vezes o número de acionistas pessoas físicas nos últimos três ou quatro anos. E isso se deve basicamente à taxa de juros. Até pode-se dizer que é consequência de empresas que souberam se comunicar, mas não é: o motivo é a taxa de juros. Ela fez que pessoas que não investiam em ações começassem a comprá-las para rentabilizar suas aplicações financeiras, tendo em vista que a taxa de juros está em $2 \%$. E no Brasil, vocês sabem, estávamos acostumados com a segunda maior taxa de juros no mundo. Surgiram muitas consultorias e empresas que estavam tentando ajudar a educação financeira das pessoas porque elas iam buscar informação. As empresas conseguiam explicar para essas pessoas, tinham uma comunicação direta e muito boa com pessoa física e isso ampliou fortemente o investimento em ações. Outro efeito foi a pandemia, que fez com que a mudança na comunicação financeira fosse drástica e rápida. Em um passado recente, se você quisesse conversar com alguém em Londres, você comprava uma passagem, pegava um avião, ficava uma semana fazendo reuniões. Passavam dois dias e se você quisesse falar com um gestor de fundos no Rio de Janeiro, precisava pegar um avião. Hoje você faz tudo de forma eletrônica. Essa mudança cultural estava sendo feita devagar, mas veio a pandemia e fez essa inflexão na forma de comunicação. Então, eu vejo uma mudança muito grande nesse segmento de comunicação financeira. Não voltaremos ao patamar anterior. 
ORGANICOM - Essa perspectiva de aumento de investidores pessoa física é positiva? Isso pode colocar o Brasil em um cenário positivo de interesse de abertura de capital por parte de outras organizações?

GERALDO SOARES - A gente está em um ciclo virtuoso no mercado de capitais. A pessoa física compra em volume menor, mas como é uma quantidade muito grande, isso traz estabilidade e tendência de valorização da ação. Se você olhar no médio e longo prazo, a pessoa física é diferente porque ela conhece a empresa, usa os serviços, compra, é cliente, fornecedora ou funcionário. Esse movimento de pessoa física é mais pulverizado, com mais estabilidade em comparação com os movimentos dos grandes investidores. Esses continuam, mas essa parcela significativa de pessoas físicas comprando e vendendo dá mais estabilidade à ação. Quando você sente esse efeito, novas empresas entram. Nós estamos batendo recorde de IPO'. Mais empresas abertas trazem mais pessoas, que têm fornecedores, funcionários, amigos. Mais pessoas que podem não comprar ação da empresa $X$, mas como funcionária da empresa $Y$, ela vai comprar ação da empresa que trabalha e vai entrar no mercado de capitais. Porque ela conhece a empresa, sabe que a companhia está indo bem e tem confiança para investir em ações. Cada vez que entra uma empresa, mais gente entra no mercado de capitais. Estimamos que nos próximos dois anos chegaremos a 10 milhões de pessoas físicas brasileiras no mercado de capitais, o que era inimaginável no passado. E isso muda muito a comunicação das empresas. Está mudando e vai mudar mais ainda.

ORGANICOM - Gostaríamos de falar a respeito da questão do longo prazo versus curto prazo. Temos visto uma série de iniciativas de governança corporativa, regulações da CVM, índices que valorizam a sustentabilidade etc. Por outro lado, muitas organizações que se envolvem em escândalos de responsabilidade corporativa rapidamente retomam seu valor de mercado. De que modo o mercado está preparado para avaliar o ESG, na prática, para determinar investimentos?

GERALDO SOARES - Essa é uma pergunta excelente e complicada de responder. O ESG veio para ficar por conta da pandemia. Antes da pandemia, o ESG sempre esteve na pauta do mercado investidor, mas não era uma constante. Você tinha um grupo de investidores, principalmente europeus, investidores institucionais que olhavam isso. E quando você fala de investidor estrangeiro, não é pessoa física, é um administrador de fundo de pensão, fundo de investimento, fundo de mercados emergentes, não existe pessoa física comprando ações de empresas brasileiras. Se tiver é fora da curva, é desvio padrão, é muito pouco. Então, existe o investidor institucional, que é preparado, é um analista de investimentos que estudou, que se preparou muito. Antes da pandemia, você tinha, se muito, 10\% dos investidores do mercado europeu, que avaliava ESG com seriedade. Alguns fundos ingleses, alguns fundos alemães e franceses. Eu destacaria os ingleses, mas muito focado em governança corporativa, menos em ambiental e social. Alguns até falavam no ambiental e social, mas não era muito forte. E isso acontecia na Europa porque nos Estados Unidos não havia preocupação com ESG. Isso, é claro, antes da pandemia.

Quando veio a pandemia isso mudou. A pandemia mostrou para todo mundo os problemas que as empresas tinham em sustentabilidade. Porque sustentabilidade não é apenas o social e o ambiental, é a sustentabilidade da empresa. Será que ela está preparada para manter o relacionamento com seus clientes neste momento? Está preparada para a digitalização, para proteger seus colaboradores? Então ESG entrou na pauta. A pandemia trouxe duas coisas muito fortes: a digitalização da comunicação e o ESG, que entrou de vez no jogo. Fundos que não falavam de ESG agora o têm como pauta.Eu estou atuando em ESG desde 1999. Todo o reporte de ESG do Itaú passa por mim, todos os relatórios, incluindo o relatório integrado e tudo mais. 0 que posso dizer é o seguinte: eu nunca vi, nesses 20 anos de ESG, um interesse tão grande, tantas perguntas, tantos questionamentos profundos sobre ele, desde quando começou a pandemia. É uma grande inflexão, e veio para ficar.

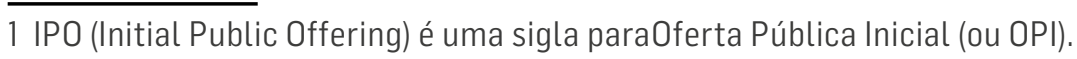


ORGANICOM - E as organizações que se envolvem em problemas?

GERALDO SOARES - 0 mercado de capitais é um microcosmos da economia. Se pensarmos sobre o que é a bolsa de valores, ela é um pedacinho da economia como um todo. E ali, naquele ambiente, o lucro impera. 0 resultado é o que impera. Se a ação de uma empresa acusada de corrupção cai $90 \%$, mas mantém o resultado financeiro, as cotações da ação voltam. É isso. É o lucro ainda que impera. Gostando ou não disso, é a realidade. É o fato concreto.

Vamos pegar um caso recente: a JBS, o caso Temer. Os controladores brigaram com o presidente da república, houve a denúncia, as ações caíram muito, venderam algumas empresas do grupo e as ações ficaram lá embaixo. Só que a JBS se reestruturou e continuou dando lucro, continuou vendendo carne para a China. Então, o resultado dela, os dividendos continuam. Você pode até ter uma contestação por conta da Governança. Os investidores podem falar: eu não consigo pagar 100\% de valor justo dessa companhia. Pago 90\%. Mas ela está dando resultado, está dando rentabilidade. Tem muito gestor que vai atrás disso e a empresa volta mesmo. Por outro lado, o que está acontecendo no mundo hoje é que você começa ter muitos índices, muitos investidores qualificados que retiram empresas do portfólio dependendo da postura dela. Isso também já está acontecendo.

ORGANICOM - É possível que a decisão de um investidor para o longo prazo esteja mais relacionada ao risco de impacto ao negócio, por conta da pressão de outros stakeholders?

GERALDO SOARES - Tem uma pressão das pessoas que compram fundos de investimentos. Você pode ir a uma reunião na assembleia e reclamar dos investimentos do seu fundo, nos aspectos sociais e ambientais. Mas isso é muito na Europa. Nos Estados Unidos a pressão é muito mais voltada à governança corporativa. Mas no mundo estão acontecendo movimentos de discussão de ESG com mais profundidade. Foi criado um novo framework de investimentos, há pouquíssimo tempo, o SASB2 pelo Bloomberg. Foi a primeira vez que eu vi uma iniciativa relevante de ESG no EUA, e isso vai dominar o mercado de frameworks no mundo. Já está dominando. Deve ficar se não o único, o mais importante. Fizeram uma série de coalisões. O IASB, a fundação da norma ambiental IFRS, já está estudando uma forma de incorporar ESG dentro das demonstrações financeiras. As quatro auditorias big four soltaram um novo frameworkcom os 21 principais pontos que as empresas precisam reportar em relação à ESG. Então estamos vendo uma padronização da discussão ESG e isso vai ser muito importante. Vai ser bom quando isso estiver bem estruturado.

ORGANICOM - Sobre o perfil dos públicos. Você já falou um pouco sobre os novos investidores pessoas físicas. Mas em comparação com os analistas de mercado, com os investidores institucionais, quais os desafios de comunicação para lidar com cada um deles?

GERALDO SOARES - A área de relações com investidores sabe lidar muito bem com o investidor qualificado. Com o analista de investimento, o portfólio manager. 0 grande desafio é lidar com a pessoa física. Todas as áreas de relações com investidores no Brasil estão sofrendo com isso. Mesmo porque a pessoa física normalmente tem vários chapéus. Ele é ao mesmo tempo acionista, consumidor, fornecedor, tomador, jornalista, acadêmico. Ele está no país que é a sede. A comunicação com esse

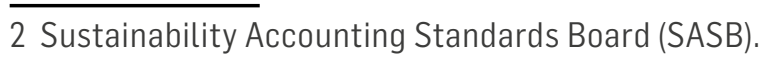


público é uma dificuldade muito maior; e por que é muito maior? É muito fácil você ter só a linguagem do mercado financeiro e ficar falando só em ebitda, ROI, pay out, dividend yield. Existe o jargão do dialeto do mercado financeiro, e é fácil usá-lo. Quando você fala para um investidor pessoa física, a gama de conhecimento é muito dispersa. Você pode encontrar desde uma pessoa sofisticada, com grande conhecimento de mercado, ou alguém leigo, que só quer falar de dividendos. 0 profissional de RI precisa saber falar a linguagem daquela pessoa, que é totalmente diferente do analista. Eu já tive que atender durante uma hora e meia uma pessoa de 82 anos para explicar o que era tag along. E ela não entendeu. Eu fiz de tudo, expliquei de diferentes formas. Houve um momento em que prometi para ela que o banco não estava à venda, pois ela achava que o banco estava sendo vendido. Uma pessoa de 82 anos, do interior de São Paulo, que eu não sabia que tinha uma posição acionária relevante. Depois descobri que ela tinha muitas ações. Eu estava com quinhentos compromissos, mil coisas para fazer, e fiquei um longo tempo com ela. Eu tive que explicar em uma linguagem totalmente diferente do usual. Precisava ser a linguagem dela, não a minha.

ORGANICOM - É papel dos profissionais de relações com investidores educar esses públicos para entender o mercado financeiro? Ou a quem cabe esse papel?

GERALDO SOARES - Esse profissional também tem esse papel. Quando você vai se comunicar com pessoa física, precisa ser mais didático, mais informal. Eu não posso escrever pay out. Eu preciso escrever o conceito, colocar uma fórmula. Não posso só usar um jargão, por exemplo, dividend yield, porque existem três formas de calcular. Como eu explico a importância do dividend yield para se fazer uma análise adequada? Então, ele tem sim, que sair do dialeto e ir para uma comunicação mais informal, didática, em uma comunicação financeira mesmo.

ORGANICOM - Muitos públicos têm comprado quotas de capital para dialogar com o board como acionistas e pautar temas de seus interesses. Mas o objetivo desses públicos é diferente dos demais investidores, é uma postura ativista. Como você observa a pertinência e os resultados desses movimentos que têm sido intensificados?

GERALDO SOARES - Você está falando dos ativistas? Temos uma característica no Brasil um pouco diferente, que é de muitas empresas com controladores. É diferente dos EUA e da Inglaterra, nos quais as empresas têm controle mais pulverizado. Nos EUA até há muitas famílias controladoras, mas aqui no Brasil o grande capital cresceu com famílias controladoras. Então, as assembleias ainda não têm muita abertura, pois quem define a assembleia é o controlador. 0 ativismo aqui é menor em comparação com outros países porque é difícil um ativista ter muito espaço em assembleias, principalmente em grandes empresas. Quando uma empresa não tem controlador - que é algo em crescimento paulatino nos últimos dez anos - porque várias empresas já pulverizaram capital, o ativista tem um peso enorme. Vou dar um exemplo: tem um fundo chamado Aberdeen $^{3}$, gigantesco, que são muito ativistas em Governança Corporativa. Eles discutem até remuneração de executivos. Agora, eles vão discutir em uma empresa que tem controle? Não adianta. Ele vai discutir, mas as definições saem de um controle. Eu estou falando da realidade. 0 ativismo só funciona realmente quando você tem uma pulverização de capital. Esses fundos, como Aberdeen e Fidelity participam em diversos tipos de organizações, mas o efeito deles é muito menor em empresas que têm controladores. Até a maneira de eles abordarem é um pouco diferente. Agora, tem ativistas dos dois lados. Tem o ativista bom e 0 ativista ruim, tem 0 ativista urubu, tem de tudo, pois onde tem dinheiro, você acha de tudo. Mas os ativistas em geral estão buscando agregar valor à companhia, para eles ganharem dinheiro no investimento deles. No fundo, é isso.

3 Para maiores informações: https://www.aberdeenstandard.com/pt-br/brazil/fund-range 
ORGANICOM - Existe também um outro perfil de ativismo em assembleias, geralmente protagonizados por comunidades locais, ONG's, que compram cotas de capital. Mesmo que minoritários, buscam participar de assembleias para promover discussão, confronto, enfrentamento. Desejam trazer para o debate pautas que não estão na matriz de materialidade, que não estão na pauta dos fóruns de investidores. Como você observa a participação cada vez maior desses grupos?

GERALDO SOARES - É fundamental. Eu falo que a empresa tem que ser porosa, tem que ouvir seus stakeholders, seja em uma assembleia, ou fora dela. Quando eu falo porosa, eu me refiro ao exemplo de uma esponja. Tem que saber absorver o que o mercado está falando dela, porque senão, ela não sobrevive. Quando eu falo de sustentabilidade, significa você dialogar com seus stakeholders, seja comunidade local, clientes, funcionários. Não é toda a sociedade, é com quem ela realmente tem contato. Quando a gente fala de stakeholder, estamos falando daquele público que está no entorno da empresa. No caso do Itaú, por exemplo, é a comunidade no entorno de uma agência que é afetada, não é São Paulo inteira. Tem muita gente que confunde sustentabilidade pensando que as empresas têm que resolver o problema do país. Tem um certo engano no conceito de sustentabilidade. Eu preciso conseguir dialogar com meus stakeholders, ter uma conversa extremamente aberta, ou seja, não significa que eu vou fazer tudo o que o stakeholder quer, mas eu vou ouvir a opinião dele e tomar uma atitude em relação a isso. E aí ele decide o que ele quer fazer. Com base em minha decisão, ele decide. Porque a empresa pode dizer "isso não me interessa, não é o momento, não concordo com você". E aí ele toma a decisão dele. Mas essa relação de diálogo transparente é fundamental. 0 que hoje os índices e as agências de rating em sustentabilidade estão pedindo para as empresas é: transparência. Não importa se uma empresa de cosméticos, por exemplo, é contra ou a favor de testes em animais. É preciso ser transparente em dizer se faz ou não faz. E a sociedade vai decidir se tem relacionamento com ela ou não. 0 que se pede é transparência na comunicação, qual a sua atitude em relação ao tema. Me mostre o que você faz. E com base nisso eu vou decidir qual será o meu relacionamento contigo. Então, para a participação desses stakeholders ativistas, seja em assembleia, seja por meio de cartas, a empresa tem que estar aberta. Ela tem que ouvir. Se ela tem uma postura de diálogo, não importa se é assembleia, se é uma reunião Apimec, se é uma teleconferência, se é reunião individual com eles. A questão é: qual é minha abertura, qual é minha postura, qual é o meu desejo de informar? Isso é 0 mais importante de tudo.

ORGANICOM - Sobre o aspecto das tecnologias, como o mercado está se comportando em relação a vazamento de informações? A área de RI precisa garantir sigilo, pois o risco de informação privilegiada é muito sensível. Como vocês lidam com riscos, nessa possibilidade tão intensa de vazamentos de informações?

GERALDO SOARES - Quando começou a pandemia eu tinha uma dúvida enorme se funcionaria o sistema home office no caso de informações confidenciais. Estou aqui confidenciando para vocês essa preocupação. Eu ficava em dúvida: será que não vai vazar informação? Antes da pandemia, estávamos começando o home office na companhia, uma vez por semana. Minha equipe fazia um dia por semana, mas eu não me sentia confortável. De repente, eu estou cinco dias por semana trabalhando em casa. E não é que os sistemas funcionaram? E não é que a segurança está funcionando? Não vazou nada. É que eu estou em um banco, e um banco tem características diferentes de uma indústria, de uma empresa de serviços. Temos o sigilo bancário, ou seja, a segurança é muito maior que a de uma empresa de serviços, por exemplo, pelo tipo de nosso negócio. Mas a questão do vazamento de informações é muito grave. Vamos pegar como exemplo a Lei Geral de Proteção de Dados (LGPD). Já aconteceu vazamento de informações de muitos brasileiros em algumas empresas. Outras também se envolverem em vazamento, não captura, mas de divulgação feita errada, que alguém "apertou um botãozinho errado", divulgou o que não deveria ter saído. Aconteceu na pandemia com empresas grandes, e isso sempre pode acontecer. Mas a LGPD veio para ficar. 0 risco cibernético é um dos maiores que temos hoje, não apenas de informação confidencial, mas de risco de dados. 0 mundo 
todo está se preocupando com isso. Já reportamos há cinco anos nossas ações para evitar risco cibernético, com regras muito rígidas. É um risco do dia a dia de todas as áreas, uma preocupação diária da gestão.

ORGANICOM - Sobre esse processo de escuta, de ouvir stakeholders e o mercado, você falou que a organização precisa ser uma esponja. De que modo a comunicação influencia e apoia a gestão de uma organização para entregar mais resultados?

GERALDO SOARES - Qualquer pessoa pode chegar para o presidente de uma organização e tentar recomendar: "temos que ir por esse caminho". Mas se chega a um investidor que tem 1 bilhão de dólares investido na companhia, e diz: "eu acho que vocês têm que ir por esse caminho", o cenário muda. No mercado financeiro tem muito dinheiro envolvido, são muitos recursos. É o valor de mercado da companhia, é o futuro da companhia, é como ela é vista. 0 olhar e a abordagem de um grande investidor ou do mercado como um todo influencia muito a gestão. Um dos stakeholders que mais influenciam a gestão é o investidor.

ORGANICOM - Nesse sentido, há uma crítica comum no mercado de comunicação sobre a transparência de uma companhia estar voltada apenas ao público investidor. Uma série de informações de interesse geral, de diversos públicos, sobre governança, sobre sustentabilidade, estão apenas na área de relações com investidores no site.

GERALDO SOARES - A área de relações com investidores (RI), não apenas no Brasil, mas no mundo inteiro, tem se tornado a grande área institucional das empresas. Não de marketing, mas de comunicação institucional. É ela que conhece a história da empresa, assim como as informações sobre a sustentabilidade. Hoje, em muitas organizações, os reportes de sustentabilidade estão indo para RI. É uma linguagem diferente, outro dialeto e estão indo para a área de RI. E essa área está em contato com muita gente, com públicos diferentes que têm muito interesse na companhia; e consegue entender como se comunicar com diversos públicos. Consegue pegar uma coisa que tem um dialeto diferente e transformar isso em uma linguagem muito mais acessível, a um público muito maior. Por exemplo, o relatório anual ou relato integrado não fica mais no marketing. Em grande parte das empresas, está na área de relações com investidores.

ORGANICOM - Sobre essa interação da área de RI com comunicação corporativa, você comentou sobre reportes que estão sendo incorporados pela área de RI. De que modo essas duas áreas dialogam?

GERALDO SOARES - Tem que ser um diálogo e um respeito mútuo muito grandes. 0 Codim ${ }^{4}$, por exemplo, que agora foi extinto, recomendava a existência de um comitê de divulgação e negociação dentro das empresas. 0 que é o comitê de divulgação? É um grupo na empresa que vai discutir tudo o que uma empresa divulga: um fato relevante, um comunicado ao mercado, um relato integrado, um relatório anual, o relatório para a SEC, o formulário de referência. E por que o Codim sempre sugeriu o comitê, mesmo não sendo obrigatório, sendo voluntário? Para você ter diversas áreas da empresa, sob a presidência de relações com investidores, como responsável pelos reportes financeiros, discutindo como a empresa precisa divulgar as informações ao mercado. Desde o press release para imprensa até o fato relevante. No banco temos há muito tempo 0 Comitê de Divulgação e Negociação. Ele é fantástico para definir a estratégia de comunicação e qual o papel de cada um

4 Comitê de Orientação para divulgação de Informações ao Mercado. 
para essa comunicação. Todas as áreas têm representação no comitê: relações com imprensa, marketing, institucional, Rl, jurídico. Discute-se o que, o como e a forma de comunicar. Aqui no banco as reuniões são trimestrais, mas fazemos reuniões extraordinárias quando necessário, até por telefone. 0 comitê ajuda e é fundamental para esse relacionamento.

\section{ORGANICOM - Frente a esse cenário, o que observa de uma boa prática de RI que merece ser compartilhado?}

GERALDO SOARES - Bom, ainda não temos modelos ideais. Todas as empresas no mundo estão testando a melhor forma de atender a pessoa física, mas não existe um consenso. Existem algumas práticas que já começaram a se destacar e outras que já são criticadas. Por exemplo, empresas que falam demais estão sendo criticadas. 0 over exposure, aquela empresa que quer estar em todos os canais, que quer fazer tudo e que não escolhe uma estratégia de comunicação adequada está sendo criticada. A comunicação tem que refletir a empresa, o que a empresa é, as características dos executivos, da cultura da empresa. Ninguém é igual. Pode ser que uma prática seja ótima para a minha empresa, mas não seja adequada para a sua, em função das características.

O que o mercado investidor de pessoa física tem gostado muito é do uso de vídeos. Por exemplo, a prática de uma empresa divulgar um resultado e na sequência divulgar um vídeo explicando o resultado, em 10 minutos, explicando quais são os grandes drives da companhia, de forma didática, com uma linguagem diferente. Mas nesses vídeos não pode falar pay out, não pode falar dividend yield: é proibido falar termos em inglês. E nessa linguagem, nesse tipo de ferramenta, o vídeo está sendo bem-visto.

É importante destacar que a pessoa física não é um público que aciona muito a companhia. Então se uma empresa tem 500 mil acionistas pessoa física, a área de RI não tem demanda proporcional, não é um volume gigantesco de pedidos. Quando você coloca uma teleconferência de resultados, eles ouvem. Você coloca à disposição uma ferramenta de WhatsApp para quem está assistindo à teleconferência, e mandam muitas perguntas, mas não participam da teleconferência. Não sei qual o motivo dessa postura. Talvez fiquem ouvindo os analistas com um nível de conhecimento diferenciado e não se sintam confortáveis para participar. Eles preferem ficar no WhatsApp conversando, discutindo entre eles. Mas quando acaba a teleconferência, vão embora. E você pensa: "Ah, aquele pessoal vai te questionar". Mas não. Você só vai voltar a vê-los depois de três meses. Quando fazíamos as reuniões Apimec nas cidades, as pessoas perguntavam muito, mas durante a reunião. Depois, mesmo você entregando cartão de visitas, não faziam perguntas. Só no outro ano fariam novas e muitas perguntas. É claro que quando sai uma notícia nos jornais, principalmente o investidor pessoa física, ele manda e-mail, questiona, mas não solicita informações por telefone. A interação é diferente. Todos os canais precisam estar abertos: e-mail, vídeo, mas é preciso saber qual canal vai ser utilizado. Podcast tem sido muito utilizado, por ser didático, por exemplo: por que o dividendo é importante para a minha companhia, de maneira didática, em seis, sete minutos? Esse canal tem sido bem utilizado, com repercussão muito boa, os públicos retransmitem por WhatsApp. 0 site continua sendo muito necessário para pessoa física (PF), mais aberto, didático, em que as pessoas consigam navegar e com uma linguagem que as pessoas entendam. Devido à pandemia, os principais canais são vídeo, podcaste site. Está aumentando a interação de PF, mas eles não são proativos, são reativos de forma geral. Por exemplo, o Itaú, com 500 mil pessoas físicas, tem baixa demanda de solicitações proativas de PF. 
GERALDO SOARES - O profissional de RI, primeiro, tem que conhecer finanças, contabilidade, balanço. Se ele não entender, não vai conseguir conversar com ninguém. Porque ele vai atender o aposentado de Peruíbe e o trader de Londres. Com 0 aposentado ele vai precisar ficar duas horas no telefone e com o tradervai ter cinco minutos. Com um, ele vai usar termos técnicos, com o outro, vai discutir os dividendos, a quantidade de agências, de funcionários. São dois perfis totalmente diferentes. E ele precisa saber atender esses dois públicos. Além de finanças é fundamental a comunicação, uma pessoa que saiba se expressar. Existia o estereótipo de contador, mais fechado, mas ele precisa se comunicar bem inicialmente na escrita, para um e-mail em resposta ao acionista, que mesmo sendo coloquial, tem um formalismo. Em terceiro, conhecer legislação societária é importantíssimo. Ele precisa saber a diferença entre um comunicado ao mercado e um fato relevante, a diferença entre um relato integrado e um formulário de referência, saber o que implica cada ação e cada movimento dele. Se tiver ações no exterior, conhecer a legislação societária norte-americana, por exemplo, se estiver listado em Nasdaq. E a questão da digitalização: saber utilizar as ferramentas disponíveis hoje no mercado, saber utilizar o melhor dessas ferramentas. Eu colocaria essas quatro grandes skills de um profissional de Rl: finanças, legislação societária, comunicação e digitalização.

ORGANICOM - Você sugeriria algum tema a ser aprofundado na pesquisa acadêmica, no tema Rl, olhando a perspectiva da comunicação? O que você não vê sendo discutido e aprofundado, mas sente que é uma demanda?

GERALDO SOARES - Tem algumas. Vamos falar primeiro de ESG, que cada vez mais está sendo integrado à discussão financeira. Até um ano antes da pandemia, o ESG parecia um dialeto, uma discussão diferente da área financeira. Hoje isso está se juntando, tanto que eu falei da fundação IFSR, que até setembro vai lançar o primeiro trabalho para unificar de modo obrigatório as informações ESG dentro do balanço de uma empresa. Mas onde eu quero chegar é: quando tiver que reportar, como eu integro essas informações? Faltam trabalhos, falta reflexão profunda, acadêmica, sobre como se integra uma questão ambiental por parte da Vale, em Brumadinho, por exemplo? Como eu discuto vazamento de óleo na Petrobras? Estamos mudando de patamar. 0 que importava na materialidade da companhia eram os dados financeiros: lucro, ROI, perspectiva, retorno, dividendos. Estamos entrando com outros componentes de materialidade a que a comunidade não está acostumada porque tem um dialeto diferente. Então como os outros drivers se incorporam a esses? Precisam se integrar, porque se não se integrarem, não são verdadeiros. Não adianta falar "eu sou ESG" se no dia a dia da minha companhia não integrei os componentes ESG, que não é ser apenas filantropo. O ESG é incorporar na sua operação o que tem a ver com o seu core business, o que você faz no negócio. Vamos pegar o caso da JBS: A questão na JBS não é se incentiva o consumo de carne ou não. 0 ponto é: você tem rastreabilidade do boi que compra? Sabe se está vindo da Amazônia ou não? É isso que importa na sustentabilidade, porque se tem consumidor, ela vai produzir carne. Se quero ser sustentável na Amazônia, no Centro-Oeste, no Pantanal, tenho que ter rastreabilidade do boi, de como ele veio, de maneira ética, integral, correta. Saber como isso foi medido, ter uma auditoria. Isso vai fazer até com que o boi tenha mais valor, que eu consiga vender ao mercado europeu. Ou seja, tem que integrar sustentabilidade na companhia e não ter apenas um discurso ESG.

Faltam estudos, trabalhos acadêmicos de como se comunicar. Existe o financeiro de um lado e o ESG do outro lado, que é um dialeto também. Se colocar duas pessoas de ESG conversando e não for iniciado, eles vão conversar durante uma hora e você não vai entender nada. E é a mesma coisa no mercado financeiro. Como eu integro essas duas comunicações de uma maneira didática, para todo mundo entender? Isso é um desafio grande.

0 desafio é descer do "juridiquês" para uma linguagem mais coloquial. Muitas vezes você lê um comunicado ao mercado, um fato relevante, e sabe que ele foi escrito pelo advogado da companhia. Mas o jeito do advogado escrever é pensando na defesa, né? Ele pensa em como ele pode se defender. E se a empresa tem o desejo de informar, ela precisa ser mais 
transparente e não ter essa postura defensiva. Um benchmarking de comunicação muito legal é o do Warren Buffet, da Berkshire Hathaway. Ele escreve de um jeito interessante, ele fala: "Eu errei aqui, eu errei lá, eu comprei ação errada. Charlie Munger mandou eu comprar ação x, eu não comprei.". Ele é muito transparente, é muito claro. Aqui no Brasil as empresas têm receio de falar dos seus problemas, onde erraram. E é meio cultural. 0 brasileiro não fala dos erros dele, só fala dos acertos. E isso em uma comunicação institucional pode atrapalhar, porque a empresa tem que ser transparente, tem que falar em que errou. 0 mercado está exigindo isso cada vez mais. Os investidores, os stakeholders querem saber e as empresas precisam comunicar sobre temas, por exemplo, como assédio moral ou assédio sexual. E não adianta falar que "ah, eu tenho uma política, tenho um comitê que vai analisar os casos". Os investidores querem saber: quantos casos tiveram, quantas pessoas foram punidas e qual a punição; quantas pessoas foram demitidas e por quê. Isso acontece com diversos temas, com processos trabalhistas, por exemplo. Está tendo uma pressão muito grande e as empresas estão começando a abrir isso ao mercado, a falar dos erros e não apenas os acertos. 